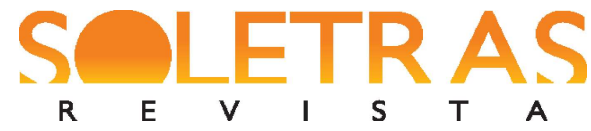

\section{Castro Lopes e a crônica de Machado de Assis: discussão linguística nas páginas da Gazeta de Notícias}

\begin{abstract}
Resumo: Este artigo visa demonstrar como o escritor Machado de Assis (1839-1908) contribuiu para a formação do gênero crônica no Brasil, utilizando-se das dimensões e da abrangência do suporte jornal. Abordamos especificamente suas posições acerca das propostas de Castro Lopes (1827-1901), famoso filólogo do final do século XIX que propôs substituir, na língua portuguesa, alguns estrangeirismos por vocábulos novos, criados por ele em maioria a partir do latim. Para tanto, analisaremos três crônicas publicadas sob pseudônimo e cuja autoria foi atribuída ao autor fluminense em 1955. As crônicas da série Bons Dias!, lançadas no periódico Gazeta de Notícias entre os anos de 1888 e 1889, tratavam majoritariamente dos grandes acontecimentos políticos da época, o que torna os três escritos selecionados como isolados dessa temática. Sendo assim, mostramos que o autor dessas crônicas, através de um discurso essencialmente retórico, tentava persuadir seus leitores a refletirem sobre as ideias do mencionado latinista. Para embasar o nosso trabalho, valemo-nos principalmente de Candido (1992) e Meyer (1992) no tocante ao estudo da crônica, assim como de Lausberg (1967), para a compreensão das técnicas da retórica. Também subsidiamos nossa análise em Farias (2013), Gledson (2008), Barbosa (2011), Betella (2006) e Magalhães Júnior (1985; 2008).
\end{abstract}

Palavras-chave: Machado de Assis. Castro Lopes. Gazeta de Notícias. Crônica. Retórica.

\title{
Introdução
}

As crônicas constituem certamente uma das partes menos conhecidas da extensa produção escrita de Machado de Assis (1839-1908). Estes escritos, de um gênero considerado "menor" por alguns teóricos, segundo Candido (1992, p. 13), podem ter sido postos de lado devido à deficiência de compreensão de seus temas e, por consequência, dos artifícios utilizados em sua construção. Uma leitura que recupere as informações do contexto de produção da

\footnotetext{
${ }^{1}$ Doutorando em Letras pela Universidade Federal da Paraíba (UFPB). Brasil. E-mail: valnikson18@ @hotmail.com Orcid: http://orcid.org/0000-0003-1253-4379

2 Doutora em Literatura Brasileira pela Universidade de São Paulo (USP). Professora titular da Universidade Federal da Paraíba (UFPB), vinculada ao Programa de Pós-Graduação em Letras (PPGL) da mesma instituição. Bolsista de produtividade e pesquisa do Conselho Nacional de Desenvolvimento Científico e Tecnológico (CNPq). Brasil. E-mail: socorrofpbarbosa@hotmail.com Orcid: http://orcid.org/ 0000-0002-4399-9972
} 
crônica e sua relação com o suporte jornal contribui para elucidar a importância do gênero para a obra machadiana e para a história da literatura brasileira.

Machado dedicou muitos anos ao gênero crônica, publicando seus escritos semanalmente em diversos periódicos cariocas. Através delas, acompanhou de perto a vida social, política e cultural do país, suas transformações. As crônicas podiam ser divertidas ou sérias, mas nunca deixavam de apresentar um ponto de vista único. Tais escritos revelam não só um desejo de prender o leitor, mas também de forçá-lo a pensar (GRANJA, 2008). O interesse pelas crônicas torna-se especial, nesse sentido, em relação ao que podem revelar sobre as opiniões do escritor aos temas cotidianos, além de informar sobre a relação que mantinha com o público leitor e com a própria imprensa oitocentista brasileira.

O presente artigo discute como Machado de Assis, no final do século XIX, através da crônica, opinou sobre o projeto linguístico promovido pelo filólogo Castro Lopes (1827-1901) que criou uma variedade de neologismos, baseados principalmente na língua latina, para substituir galicismos e anglicismos comuns ao português falado na época. Para isso, analisaremos três crônicas publicadas na coluna Bons Dias!, do periódico carioca Gazeta de Notícias: a de 7 de março de 1889 , a de 22 de março de 1889 e a de 20 de abril de $1889 .{ }^{4}$ As crônicas, assinadas com o pseudônimo Boas Noites, foram atribuídas ao escritor fluminense apenas em 1955 pelo pesquisador José Galante de Sousa (1913-1986), que encontrou a prova que assinalava Machado como autor das crônicas em um manuscrito presente no acervo da Biblioteca Nacional. Tratava-se de uma lista de identificação de anônimos e pseudônimos organizada pelo jornalista e escritor José Alexandre Teixeira de Melo (1833-1907), feita provavelmente quando ele trabalhava naquela importante biblioteca pública, entre 1875 e 1900 . Tal descoberta acabou registrada na obra Bibliografia de Machado de Assis (1955).

\footnotetext{
${ }^{3}$ Dr. Antônio de Castro Lopes (1827-1901) foi uma figura curiosa das letras brasileiras no século XIX. Latinista famoso, ele publicou dicionários e livros de caráter linguístico, além de uma variedade de escritos tematizados em astrologia, espiritismo e homeopatia, também exercendo o ofício de professor, médico, teatrólogo e poeta. Segundo Bortolanza (1999), fundou o primeiro banco hipotecário do país, o "Banco Predial", além da "Companhia Serviço Doméstico", da "Caixa Mutuante" e da primeira "Sociedade Cooperativa de Consumo". Era conhecedor de tudo, um "Larrousse ambulante" nas palavras de V. de Algerama (BORTOLANZA, 1999, p. 303), que tinha resposta para qualquer questão, mesmo que nem sempre bem fundamentada.

${ }^{4} \mathrm{O}$ artigo apresenta um recorte do trabalho de conclusão de curso intitulado Machado de Assis e os neologismos de Castro Lopes: reflexões linguísticas em crônicas de Bons Dias!. A pesquisa foi apresentada em 2015, como requisito obrigatório para aprovação no grau de Licenciatura em Letras (Habilitação em Língua Portuguesa) da Universidade Federal da Paraíba (UFPB), encontrando-se disponível no repositório da referida instituição.
} 
A proposta de analisar as crônicas de Bons Dias! surgiu da leitura e da descoberta das três amostras "isoladas" dentro da linha temática da referida coluna. Publicada entre os anos de 1888 e 1889, no jornal Gazeta de Notícias, sendo recolhida totalmente em livro pela primeira vez em 1990, com edição organizada e comentada pelo estudioso John Gledson, a série é geralmente estudada pela relação com as opiniões políticas de Machado. ${ }^{5}$ As três crônicas selecionadas para o nosso estudo "fogem à regra" da coluna, que tratava de temas mais ligados aos grandes acontecimentos parlamentares, trazendo comentários pautados em uma série de pequenos artigos iniciada por Castro Lopes também na Gazeta criticando os estrangeirismos. Investigamos a hipótese de que o autor das crônicas, além de se apoderar das possibilidades advindas do gênero, faz uso de uma composição discursiva modulada pela retórica visando persuadir seus leitores a refletirem sobre as ideias do latinista.

\section{Machado de Assis e a crônica}

Em uma crônica da série Histórias de Quinze Dias, publicada originalmente em 1 de novembro de 1877 na revista Ilustração Brasileira, Machado de Assis mostrou uma interessante visão acerca da criação do gênero:

Não posso dizer positivamente em que ano nasceu a crônica; mas há toda a probabilidade de crer que foi coletânea das primeiras duas vizinhas. Essas vizinhas, entre o jantar e a merenda, sentaram-se à porta, para debicar os sucessos do dia. Provavelmente começaram a lastimar-se do calor. Uma dizia que não pudera comer ao jantar, outra que tinha a camisa mais ensopada do que as ervas que comera. Passar das ervas às plantações do morador fronteiro, e logo às tropelias amatórias do dito morador, e ao resto, era a coisa mais fácil, natural e possível do mundo. Eis a origem da crônica (ASSIS, 2008, v. 4, p. 387).

\footnotetext{
${ }^{5}$ As crônicas também se encontram disponíveis ao público no acervo digital do Ministério da Educação (MEC), mas sua transcrição utiliza como fonte as versões em livro da série, não correspondendo à grafia original dos jornais, além de apresentar algumas supressões de parágrafos ou frases completas, cortes estes que comprometem a compreensão dos escritos.
} 


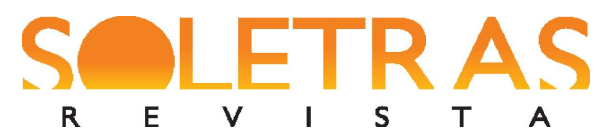

N. 40 - 2020.2 - VALNIKSON VIANA OLIVEIRA

SOCORRO DE FÁTIMA PACÍFICO BARBOSA

O escritor apontou a possibilidade de o começo ter sido baseado no diálogo, na interação entre vizinhas. De fato, a gênese imaginária de Machado aponta alguns aspectos da crônica desenvolvida no Brasil durante o século XIX, como a simplicidade da conversa, a linguagem coloquial, as observações particulares sobre os fatos corriqueiros do dia a dia. Entretanto, o termo "crônica" requer muita atenção quando vinculado aos escritos publicados nos periódicos oitocentistas nacionais. Ora designava um gênero propriamente dito dentro do suporte Folhetim, ora o próprio suporte, uma seção no jornal que abrigava escritos de caráter diverso, mas sempre nascendo do ocasional, sem prescindir aos assuntos mais sérios.

As colunas que recebiam o nome de "crônica" traziam escritos de aplicabilidade distinta. Algumas tratavam de assuntos ligados tanto aos acontecimentos diários quanto à análise ou à divulgação da literatura feita no Brasil e em Portugal, como a seção do periódico O Futuro. Outros segmentos de mesma alcunha também ofereciam escritos sobre o próprio ato de escrever, enquanto já se podia encontrar na Revista Brasileira uma seção de escritos críticos denominada Crônica literária. Na revista A Estação, o espaço de título Croniqueta abrigava desde apostas no Jóquei Clube do Rio de Janeiro até a programação nos teatros, além de discutir os assuntos ligados a parlamentares e aos eventos culturais de maior destaque. Contudo, verificamos que o gênero crônica, em território nacional, derivou do artigo de cunho variado e descontinuado publicado no mesmo espaço do jornal em que era publicado o romance de folhetim, sendo que este último se firmou mais cedo enquanto gênero e alcançou mais sucesso durante o Oitocentos.

No Brasil, a crônica não nasceu propriamente com o jornal, aparecendo em suas páginas quando este se tornou cotidiano durante o século XIX, com tiragem relativamente grande e teor mais acessível. Naquele tempo, tal gênero espelhava a natureza imediata de elaboração de seu suporte, também constituindo um espaço eficaz para a observação e a análise crítica de seu tempo. Entretanto, não era construído apenas por comentários, com os acontecimentos podendo ser utilizados como ponto de partida para a reflexão e para o exercício ficcional (BETELLA, 2006). A crônica se valia dos assuntos do dia a dia e, mesmo sem a intenção de "durar", de permanecer para a posterioridade, pertencia à esfera literária.

Antes de se configurar como o gênero que conhecemos, a crônica brasileira era conhecida como folhetim de variedades, um "artigo de rodapé" sobre as questões do dia ou da semana (CANDIDO, 1992, p. 14-15). Quando chegou ao país, o espaço chamado folhetim de 
berço europeu se adaptou à demanda dos periódicos nacionais, englobando romances e outros escritos de caráter variado em prosa ou verso. Para Meyer (1992, p. 96), o espaço folhetim nasceu ao "rés-do-chão" da primeira página do jornal, caracterizando um lugar livre dedicado ao entretenimento, o que possibilitou uma grande diversidade de produções. Foi nessa área dos jornais que muitos autores puderam exercitar a escrita, fosse ela de ordem narrativa, descritiva ou opinativa, versando sobre qualquer assunto que atraísse os leitores. Podemos afirmar que, de certo modo, o lugar-folhetim já possuía alguma autonomia em relação ao jornal, pois também apresentava temáticas que fugiam aos grandes acontecimentos que eram então foco dos periódicos.

$\mathrm{Na}$ crônica inicial da série Ao acaso, de 5 de junho de 1864, Machado de Assis demonstra utilizar o caráter versátil e cotidiano do gênero, então nascente no país, para dar sentido ao título de sua nova coluna, publicada dentro da seção Folhetim no jornal Diário do Rio de Janeiro:

O folhetim não é outra coisa mais do que o acaso, o vago, o indeterminado; é o acontecimento que há de haver, o livro que se há de imprimir, o sarau que se há de dar; é o dito que escapa, a anedota que circula, o boato que se espalha; é o capricho do tempo, o capricho da pena, o capricho da fantasia; é a chuva e o sol, a alegria e o cântico; o folhetim reside no dia seguinte, vive do futuro, sai dos ventres de todas as semanas, - às vezes Minerva armada - às vezes ridiculus mus. (Diário do Rio de Janeiro, 5 jun. 1864).

Verificamos aqui uma clara definição da crônica oitocentista: um escrito impreciso, muitas vezes contraditório, ligado essencialmente ao tempo e suas circunstâncias, que poderia tanto alcançar um realce duradouro, tamanha sua força artística e estratégica, simbolizada com a figura armada da deusa latina Minerva, como constituir um empreendimento que fracassaria logo na sua execução, como o ridiculus mus da Arte Poética do poeta e filósofo latino Horácio. De acordo com Candido (1992), a crônica herda do suporte jornal a transitoriedade e o caráter efêmero. Segundo o autor, os escritos publicados nos jornais morrem diariamente, sendo submetidos ao consumo imediato e ao esquecimento. O ambiente da notícia acaba também 


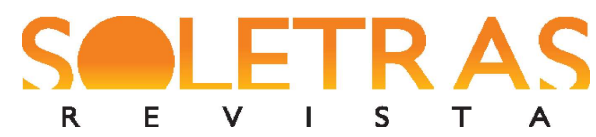

N. 40 - 2020.2 - VALNIKSON VIANA OLIVEIRA

SOCORRO DE FÁTIMA PACÍFICO BARBOSA

exercendo certa influência sobre o texto escrito, determinando sua brevidade e ligando-o diretamente ao cotidiano retratado nas páginas da publicação periódica.

Ainda em consonância com Candido (1992, p. 13), os assuntos seriam tratados nas crônicas através de uma composição aparentemente solta, com "ar de coisa sem necessidade", mas que essa despretensão se ajustaria à sensibilidade do cotidiano. Sá (1985, p. 10) aponta que a crônica seria "o registro do circunstancial" e o cronista, "narrador-repórter" nas palavras do teórico, um exímio observador de seu tempo, construindo divagações pessoais acerca de algum acontecimento através de uma linguagem despretensiosa. Ademais, o gênero também representa uma comunicação direta com o leitor, pautada em uma finalidade planejada, e não a simples transcrição de uma frase ouvida na rua. $\mathrm{O}$ escritor da crônica precisaria de um ritmo ágil para poder acompanhar a velocidade dos acontecimentos. Por isso sua sintaxe seria um tanto solta, mais próxima da conversa oral que do texto escrito.

Farias (2013, p. 56) aponta que a contribuição em jornais e revistas era imprescindível a qualquer escritor iniciante no século XIX. O jovem Machado de Assis ingressou primeiramente no ambiente das publicações periódicas, em meados da década de 1850, antes de se aventurar pelos livros. Segundo Granja (2000, p. 23), como representação inicial de sua obra, as crônicas serviriam de ponto de partida para a "análise das ideias que o escritor foi deixando registradas e que nem sempre são ideias dispersas". Até a publicação das crônicas de Bons Dias!, o autor percorreu um longo e produtivo caminho na imprensa do Rio de Janeiro, publicando muitas séries e aperfeiçoando suas técnicas de escrita sempre por trás de algum pseudônimo. Segundo Barbosa (2011, p. 272), durante o século XIX, mais do que máscaras, os pseudônimos empreendidos nos periódicos brasileiros traduziam com bastante propriedade a posição dos autores em relação ao presente histórico, aos acontecimentos políticos e sociais, bem como à linha editorial do jornal. $\mathrm{O}$ anonimato ainda possibilitava a primazia do texto escrito sobre a figura do autor, conferindo ao suporte jornal a credibilidade e a autoria daquilo que estava escrito.

Pode-se afirmar que o referido escritor fluminense acompanhou de perto a consolidação da crônica e sua evolução dentro dos jornais, iniciando sua colaboração efetiva enquanto folhetinista de variedades na década de 1860, redigindo para o periódico Diário do Rio de Janeiro. De acordo com Pereira (1998), após passar seis anos produzindo principalmente poesia e crítica literária ou teatral para alguns jornais e revistas, como Marmota Fluminense, Correio 


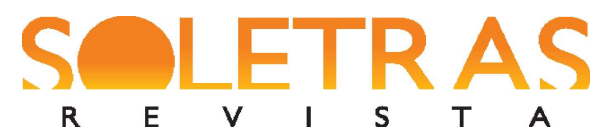

N. 40 - 2020.2 - VALNIKSON VIANA OLIVEIRA

SOCORRO DE FÁTIMA PACÍFICO BARBOSA

Mercantil e O Espelho, Machado de Assis teve seu nome associado ao Diário do Rio de Janeiro a convite do amigo e então redator principal Quintino Bocaiúva (1836-1912). O público feminino constituía o alvo comum da maioria das publicações na época, com boa parte do mercado editorial oitocentista passando a condicionar a forma de escrever dos autores à função de agradar e atrair mais consumidoras, enfocando assuntos voltados à moda e tendo na publicação do romance de folhetim um forte aliado. Segundo Farias (2013, p. 68), Machado agora teria uma "coluna fixa e um razoável salário", trabalhando em um impresso que não era voltado apenas para as mulheres, garantindo certo nível de liberdade em relação ao que poderia discutir em seus escritos.

Foi nas páginas do jornal Gazeta de Notícias - em que estreia em 1883 - que Machado publicou mais de três quartos de sua produção no gênero crônica (GLEDSON, 2008). Com o pseudônimo Lélio, passou a escrever para a seção Balas de Estalo, que já existia naquele jornal desde 1882. Sua contribuição, quase diária, vai de 2 de julho de 1883 a 22 de março de 1886, com crônicas de tom mais sucinto e direto. Seis meses depois, iniciou a série de crônicas dialogadas $A+B$, utilizando o pseudônimo João das Regras. Os temas aqui eram debatidos por dois personagens designados apenas por letras, cujo diálogo era compartilhado com os leitores. A coluna teve vida curta, durando apenas sete publicações entre 12 de setembro e 24 de outubro de 1886. Entretanto, o escritor logo iniciou a Gazeta de Hollanda, nova série com crônicas em verso assinadas com o pseudônimo Malvolio. Os quarenta e nove escritos foram publicados de 1 de novembro de 1886 a 24 de fevereiro de 1888 (GLEDSON, 2008). Os escritos seguiam outra configuração, mas continuavam na mesma linha temática da coluna $A+B$, comentando fatos que viravam notícia no cotidiano oitocentista.

Machado iniciou a coluna Bons Dias! pouco mais de um mês após o término da última série de crônicas, em 5 de abril de 1888. As novas crônicas seguiam uma mesma fórmula, não possuindo título, sendo iniciados com a expressão "Bons Dias!" e terminando com a despedida "Boas Noites", que também servia como assinatura-pseudônimo. As publicações desta coluna cessaram em 29 de agosto de 1889, contando quarenta e nove crônicas. Em 24 de abril de 1892, passa a escrever para a série $A$ Semana, agora sem esconder sua identidade. Ao todo, foram duzentas e quarenta e oito crônicas publicadas até 28 de fevereiro de 1897, quando o autor deixou de colaborar com a Gazeta de Notícias (FARIAS, 2013). A coluna foi suspensa por um mês no período em que ocorreu a Revolta da Armada, em novembro de 1893. Após oitenta e 


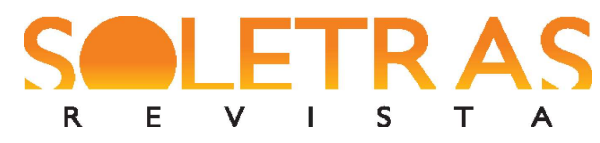

N. 40 - 2020.2 - VALNIKSON VIANA OLIVEIRA

SOCORRO DE FÁTIMA PACÍFICO BARBOSA

três crônicas publicadas, a série retornou em 1 de fevereiro de 1894. Segundo Farias (2013), com a saída do periódico, o escritor foi substituído por Olavo Bilac, que rebatizou a seção com o nome de Crônica, tendo alguns de seus escritos incluídos em coletâneas posteriormente.

Machado tornou-se funcionário público muito conhecido das grandes rodas da sociedade fluminense, tendo sido promovido inclusive, no momento da publicação das primeiras crônicas de Bons Dias!, a oficial da Ordem da Rosa, vinte e um anos depois de ter recebido o grau de cavaleiro (MAGALHÃES JÚNIOR, 2008). Com isso, a exposição da identidade de seus escritos também poderia trazer grandes chances de perda do prestígio e, consequentemente, do principal sustento. As crônicas, entretanto, acabam por revelar um escritor mais ácido e experimental, mesmo dentro do limitado espaço que estes escritos recebiam no suporte jornal.

\section{Um relojoeiro na Gazeta de Notícias}

Segundo Gledson (2008, p. 14-15), a Gazeta de Notícias foi um periódico "menos engajado politicamente", mesmo em um período marcado por grandes mudanças na sociedade, impulsionadas pelo crescimento da economia capitalista e pela passagem do Império para a República no país. Fundado em 1875, tinha uma tiragem relativamente pequena, de vinte e quatro mil exemplares, que também era vendida de forma avulsa nas ruas a quarenta réis, sem necessidade de assinatura. Essa maneira mais democrática de publicação fez o jornal abranger um maior público leitor, além de influenciar um tom mais informal aos seus escritos.

O jornal recebeu ainda a colaboração de inúmeros homens das letras, como Capistrano de Abreu, João do Rio, Euclides da Cunha, Olavo Bilac e o português Eça de Queiróz. Como vimos anteriormente, a Gazeta de Notícias também publicou a maior parte das crônicas escritas por Machado de Assis, constituindo um dos principais veículos de divulgação de sua obra. De acordo com Magalhães Júnior (2008), o escritor abandonou o pseudônimo de Malvolio sem sequer despedir-se dos leitores dos versos da Gazeta de Hollanda. Depois de uma pausa de pouco mais de um mês, deu início a uma nova série de crônicas, agora em prosa, com o título de Bons Dias!. Para Gledson (2008), a velocidade dos acontecimentos políticos justifica o abandono brusco da coluna antiga e o começo da nova. Machado precisaria de um novo formato 
para fazer seus comentários. As crônicas rimadas da série anterior tiveram a mesma duração e o mesmo número de escritos que Bons Dias!: quarenta e nove crônicas publicadas em um período de dezesseis meses. Farias (2013) considera pouco provável uma coincidência, indicando a possibilidade de encomenda de um determinado número de escritos em um espaço de tempo definido pelo jornal. Os versos da Gazeta de Hollanda traziam, assim como os diálogos da precedente $A+B$, uma nova forma de escrever crônicas.

A primeira crônica da série Bons dias! exerce a função de introduzir os propósitos da coluna. É também nela que o personagem criado para dar voz às crônicas começa a ser delineado. O cronista é associado à figura de um relojoeiro que abandonou o ofício para escrever em troca de dinheiro:

No mais é o que se está vendo; cá virei uma vez por semana, com o meu chapéu na mão, e os bons dias na boca. Se lhes disser desde já que não tenho papas na língua, não me tomem por homem despachado, que vem dizer coisas amargas aos outros. Não, senhor; não tenho papas na língua, e é para vir a têlas que escrevo. Se as tivesse, engolia-as e estava acabado. Mas aqui está o que é; eu sou um pobre relojoeiro, que, cansado de ver que os relógios deste mundo não marcam a mesma hora, descri do ofício (Gazeta de Notícias, 5 abr. 1888).

Ao longo das publicações, outros detalhes foram aparecendo em uma tentativa de envolver os leitores, solidificando o disfarce. A promessa de crônicas semanais não foi mantida, trazendo uma perspectiva de irregularidade à escrita do cronista. Em crônica de 1 de junho de 1888, ele nomeia-se Policarpo, também acrescentando detalhes relacionados à sua idade, que seria bem mais avançada que a de Machado. Segundo Gledson (2008), parece provável que a figura do relojoeiro surgiu para solidificar com ironia o "descompasso da história" vivido pelo verdadeiro autor da série no momento de sua publicação. Para o estudioso, não haveria realmente uma necessidade de consistência na criação do personagem, afirmando que as contradições que o envolvem fazem parte dos joguetes textuais empreendidos nas crônicas. Bons Dias! nasceu em torno do tema da abolição da escravidão, medida eminente no início de 1888. O paradoxo de um governo conservador promulgar uma proposta essencialmente liberal pareceu ser o motivo ideal para o início de uma nova série. As últimas crônicas, publicadas em 


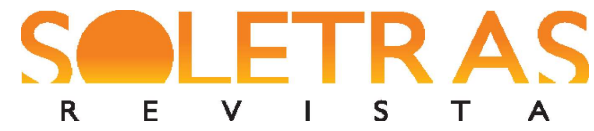

$\mathbf{R}$

meados de 1889, assinalam o contexto da implantação da República no Brasil. A coluna reagia aos acontecimentos diários, se dispondo a eles. Entretanto, não foram apenas as notícias parlamentares que receberam a atenção do cronista. Fatos cotidianos de diversas origens, a maioria vinda dos próprios periódicos e comentada pelas pessoas nas ruas, também se tornaram substrato temático de diversos escritos (BETELLA, 2006, p. 16).

\section{A discussão linguística em Bons Dias!}

Em 1889, Castro Lopes iniciou uma série de pequenos artigos na Gazeta de Notícias propondo a substituição de estrangeirismos frequentes na língua portuguesa por vocábulos novos elaborados por ele mesmo, a maioria a partir do latim. Os escritos e a busca incessante do filólogo pela pureza da etimologia da língua não passaram despercebidos por Machado de Assis, sendo tema de três crônicas da série Bons Dias!. ${ }^{6} \mathrm{O}$ três primeiros artigos foram discutidos pelo escritor fluminense na crônica de 7 de março de 1889. O artigo estreante, Neologismo indispensável - Preconício, apareceu em 27 de fevereiro de 1889, sendo dedicado ao galicismo "reclame". O latinista sugeria a substituição do estrangeirismo pelo vocábulo “preconício". Já no artigo de 3 de março de 1889, Neologismo indispensável II - Pince-Nez, Castro Lopes apresentou o vocábulo "nasóculos" para substituir "pince-nez". No dia seguinte, em 4 de março de 1889, surgia o artigo Neologismo indispensável III - Cache-Nez, propondo "focale" em substituição de "cache-nez".

A crônica de 22 de março de 1889 retoma os artigos mencionados, acrescentando comentários sobre o artigo de 11 de março, Neologismos indispensáveis $V$ - Abajur, que trata da substituição de "abajur" por "lucivelo", o de 18 de março, Neologismo indispensável VI Meeting, dedicado à troca de "meeting" por "concião", e o de 20 de março, Neologismo indispensável VII - Plomb, tematizado na alteração do termo "aplomb" por "prumo" ou "desempeno" quando no sentido figurado.

\footnotetext{
${ }^{6} \mathrm{O}$ estudioso já havia sido citado por Machado em uma crônica da série Balas de Estalo, datada de 3 de novembro de 1884, quando, ao se candidatar a deputado distrital pelo Rio de Janeiro, garantiu possuir projetos para acabar com a dívida interna e externa do país. Continuou sendo alvo de Machado em algumas crônicas da série $A$ Semana. No escrito de 25 de novembro de 1894, a se destacar, o filólogo é chamado de "nossa Academia Francesa" (ASSIS, 2008, v. 4, p. 1122).
} 
Machado de Assis ainda comentou sobre o vocábulo "chambre" em detrimento do neologismo "rocló" na crônica de 20 de abril de 1889, terceira e última da série a abordar as ideias de Castro Lopes. O galicismo não se apresenta entre os artigos do latinista publicados na Gazeta, mas sim em uma coletânea recém-lançada pelo filólogo, Neologismos indispensáveis e barbarismos dispensáveis (1889).

A série de artigos de Castro Lopes foi publicada até maio de 1889 com frequência irregular. Cada escrito funcionava de forma independente, mas ao seu final sempre havia uma nota direcionando o leitor à data de publicação do escrito precedente. Ainda muito incomodado com a grande circulação de palavras vindas de fora, Castro Lopes lançou naquele ano o mencionado livro Neologismos indispensáveis e barbarismos dispensáveis, uma espécie de extensão dos artigos vinculados na Gazeta. Logo o periódico passou a divulgar em seus últimos folhetos o anúncio do novo projeto do latinista, apresentado na Figura 1. Publicado em "muito mais de cem páginas", a obra continha aproximadamente quarenta artigos.

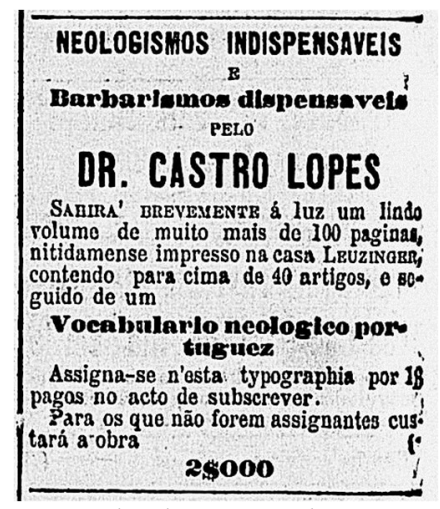

Fig.1 Anúncio de Neologismos indispensáveis e barbarismos dispensáveis (1889). Fonte: Gazeta de Notícias, 16 abr. 1889 .

Em 22 de maio de 1889, aparece no referido jornal uma pequena nota sobre a publicação, em que se informa que o "elegante volume” também possuía, além dos artigos já conhecidos pelo público leitor, um texto sobre ortografia etimológica e um vocabulário reunindo tanto os novos vocábulos como os considerados "bárbaros". Aparentemente, as 


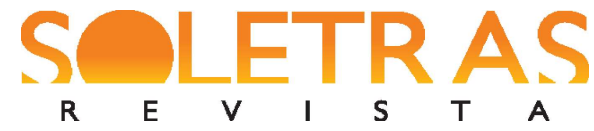

propostas linguísticas relacionadas aos neologismos empreendidas pelo filólogo alcançaram certa notoriedade, o que oportunizou a impressão da obra. ${ }^{7}$

A discussão sobre a simplificação da norma escrita em função da fonética do português transcendia os periódicos, repercutindo entre os círculos intelectuais no final do século XIX e primeiros anos do século XX. Uma reforma oficial só viria a ser aprovada em 1907, através de votações entre os membros da Academia Brasileira de Letras (dentre eles, o próprio Machado de Assis, assim como outros nomes conhecidos da imprensa nacional daquele período), em sessões realizadas de abril a julho daquele ano (RIBEIRO, 2011). De acordo com Câmara Júnior (1989), os estrangeirismos seriam empréstimos ou aquisições que uma língua faz naturalmente em virtude do contato cultural, político ou comercial com falantes de outro idioma. Martins (2008) complementa:

Podem ser empregados por força do relacionamento entre os povos, quando os nomes das coisas importadas as acompanham (verba secuuntur rem) e, neste caso, não têm praticamente valor expressivo. É o caso de batom, ruge, maquilagem, maio, mantô, short, tênis, futebol, basquete, teipe (tape) etc., que, como qualquer outra palavra, poderão ter, conforme o emprego, um valor expressivo, mas não por serem estrangeirismos; são palavras já incorporadas ao léxico português e cuja procedência grande parte dos falantes ignora (MARTINS, 2008, p. 108-109).

Como se sabe, a língua francesa era considerada "universal" no século XIX, com a França atingindo seu ápice de prestígio naquela época. Foi por meio do francês que aprendemos a "ver o mundo, que adquirimos o senso da História, que lemos os clássicos de todos os países, inclusive gregos e romanos" (CANDIDO, 1977, p. 12). Com isso, muitos galicismos foram sendo absorvidos de tal forma que quase ninguém se dava conta de estar utilizando-os. $\mathrm{O}$

\footnotetext{
${ }^{7}$ É interessante assinalar que já havia naquele tempo a discussão em torno de uma reforma da língua portuguesa no Brasil. Entre 1879 e 1881, durante a sua segunda fase, a Revista Brasileira, que já editava diversos estudos lexicográficos e etimológicos sobre diversos termos do dialeto nacional, publicou uma coleção de artigos, atribuídos ao Dr. José Barbosa Leão, a favor de uma nova ortografia do português pautada no sistema fonético dos falantes. $\mathrm{O}$ arranjo ia contra a importância excessiva dada aos estudiosos mais puristas da língua à etimologia dos vocábulos. As modificações propostas previam uma solução para a grande quantidade de variações gráficas que ocorriam mesmo nas publicações mais eruditas da língua. Tratava-se da necessidade de se elaborar um acordo ortográfico mais condizente com a realidade linguística brasileira (SILVA, 1999).
} 
mesmo aconteceu com vários anglicismos, havendo por aqui, inclusive, professores régios das duas línguas. Segundo Freyre (2000), o idioma inglês exercera clara influência no cotidiano da sociedade desde o início daquele século, em virtude das relações sociais e comerciais que o Brasil ia estabelecendo com os britânicos. Entretanto, para Castro Lopes e outros vernaculistas da época, o "vírus" dos estrangeirismos parecia contaminar o idioma nacional.

Muitos dos neologismos criados pelo referido filólogo acabaram caindo no esquecimento público, como "runimol", proposto para substituir avalanche, e "sineciforo", forjado para ocupar o lugar de "chauffeur" (nosso atual "chofer"), termos inviáveis e pernósticos na opinião de Magalhães Júnior (1985). Outros vocábulos sobreviveram de forma abatida, sendo registrados em alguns dicionários como sinônimos das palavras originais, embora muito pouco empregados na fala, como os raros "lucivelo", para substituir "abajur", "nasoculos", no lugar de "pince-nez", e "preconício", em troca de "reclame". A invenção de maior sorte foi, sem dúvida, a palavra "cardápio" (GLEDSON, 2008). O termo proposto para substituir "menu" obteve grande popularização, embora a forma francesa continue também sendo utilizada. A intervenção de Castro Lopes era muito extremada aos olhos de Machado de Assis. O escritor, como Boas Noites, tentou convencer seu público leitor de que os neologismos, imbuídos de um equivocado sentido de nacionalidade, seriam desnecessários visto que os estrangeirismos já faziam parte do cotidiano linguístico brasileiro, recebendo inclusive características nossas.

\section{A retórica em três dedos de prosa}

Carvalho (2010) aponta a retórica como uma chave de leitura para os escritos no século XIX. A formação nas técnicas de construção discursiva era imprescindível naquele período, pertencendo inclusive aos currículos escolares. Os indícios de uma cultura marcada pela retórica indicam que alguns problemas encontrados na história intelectual do Brasil poderiam ser decifrados mais facilmente com o auxílio das sugestões tiradas dos modos específicos de argumentar utilizados na escrita (CARVALHO, 2010). A retórica como base de interpretação permitiria a análise de qualquer tipo de texto escrito produzido durante o Oitocentos uma maior caracterização da sua realidade de produção e recepção. Em seu sentido amplo, a retórica 
representa a arte do discurso que é exercida por qualquer indivíduo ativamente participante na vida de uma sociedade. Ela constitui um sistema de formas de pensamento e de linguagem que podem "servir à finalidade de quem discursa para obter, em determinada situação, o efeito que pretende" (LAUSBERG, 1967, p. 75).

A retórica fazia parte da escrita da crônica oitocentista, envolvendo a utilização de artifícios da oralidade com finalidade didática ou de persuasão. Ademais, podemos perceber que este engenho também dependia da participação dos leitores. Em Bons Dias!, assim como em outras séries de crônicas empreendidas por Machado, a aparência de casualidade seria um elemento fundamental na composição textual. Entretanto, os temas eleitos viriam da própria leitura dos jornais, revelando as preocupações do cronista e sua leitura pessoal dos acontecimentos. O autor, como Boas Noites, inicia a crônica de 7 de março de 1889 questionando se tudo o que sempre escreveu estaria errado. Trata-se de uma espécie de contextualização a respeito da série de neologismos criados pelo "ilustre latinista" Castro Lopes, o tema principal a ser discutido. Ele revela não ter outro desejo senão "falar e escrever corretamente a sua língua", afirmando que se descobrir que nada do que dizia até o momento estava correto, abandonaria o ofício de escritor e passaria a falar por gestos. O tom jocoso é latente. Seguindo com o escrito, o cronista cita alguns termos em francês com que estava envolvido:

\begin{abstract}
Nunca comi croquettes, por mais que me digam que são boas, só por causa do nome francês. Tenho comido e comerei filet de boeuf, é certo, mas com restrição mental de estar comendo lombo de vaca. Nem tudo, porém, se presta a restrições; não poderia fazer o mesmo com as bouchées de dames, por exemplo, porque bocados de senhoras dá ideia de antropofagia, pelo equívoco da palavra. Tenho um chambre de seda, que ainda não vesti, nem vestirei por mais que o uso haja reduzido a essa simples forma popular a robe de chambre dos franceses (Gazeta de Notícias, 7 mar. 1889).
\end{abstract}

As iguarias francesas começam a delinear o ponto de vista do colunista. Ele demonstra certa limitação a alguns galicismos, mas expõe que determinados termos têm serventia na medida em que sua tradução "ao pé da letra" pode acarretar equívocos. Assim, enquanto passa longe das "croquettes" e come o "filet de boeuf" como "lombo de vaca", afirma não deixar de 


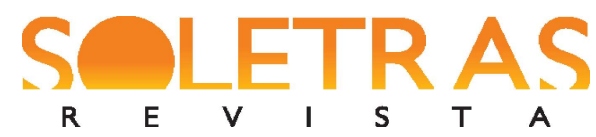

N. 40 - 2020.2 - VALNIKSON VIANA OLIVEIRA

SOCORRO DE FÁTIMA PACÍFICO BARBOSA

degustar as "bouchées de dames", petiscos bem mais compreensíveis com esta nomenclatura que com "bocados de senhoras". O colunista fecha suas considerações até aqui colocando que não usou nem usará seu "chambre”, uma espécie de roupão masculino típico daquela época, porque este seria a forma popular do "robe de chambre" dos franceses. A perspectiva menos purista em relação aos galicismos é encoberta por um véu de reprovação. São apresentados outros estrangeirismos além dos galicismos usuais naquela época, levantando-se a ideia de que a exportação de palavras e expressões seria algo bem comum:

O próprio Dr. Castro Lopes se padecer de spleen, não há de ir pedir o nome disto ao general Luculo; tem de sofrê-lo em inglês. Mas é inglês. É assim que ele aprova chale, por vir do persa; conquanto, digo eu, a alguns parece que o recebemos de Espanha. Pode ser que esta mesma o recebesse de França, que, confessadamente, o recebeu de Inglaterra, para onde foi das partes do Oriente. Schawl, dizem os bretões; a França não terá feito mais que tecê-lo, adoçá-lo e exportá-lo (Gazeta de Notícias, 7 mar. 1889).

Até aquele momento, Castro Lopes havia voltado seu ataque apenas aos vocábulos advindos da língua francesa, preferência esta que é posta em xeque, visto que a circulação de vários outros termos estrangeiros continuaria viva. Seus artigos poderiam estar pautados na verdade contra o apogeu francês no século XIX, havendo também a possibilidade de algum vocábulo aparentemente aceito pelo latinista ter sua origem ligada a outros países, inclusive à França, sem que ele soubesse. Machado de Assis manifesta encarar os termos vindos de outros idiomas como parte já intrínseca à língua portuguesa. O foco é então colocado sobre os "neologismos indispensáveis" apresentados nos artigos da Gazeta até aquele momento. O referido cronista começa analisando o "focale" em detrimento do "cache-nez", do artigo Neologismo indispensável III - Cache-Nez, publicado em 4 de Março de 1889. Ele conta que um dia se deu à procura de algo para substituir o agasalho de alcunha francesa, desconfiando de que a peça de lã não lhe ficava bem. Vai de loja em loja até encontrar um genérico advindo de um livro antigo. O "guarda-cara" é retirado de um relato sobre as mulheres da Pérsia escrito pelo jesuíta português Manuel Godinho (1630-1712), datado de 1663. De acordo com o colunista, a diferença entre o "cache-nez" francês e o "guarda-cara" português seria 


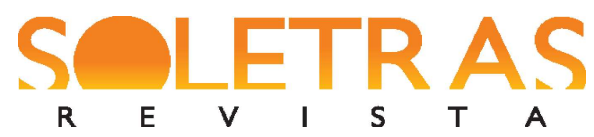

N. 40 - 2020.2 - VALNIKSON VIANA OLIVEIRA

SOCORRO DE FÁTIMA PACÍFICO BARBOSA

simplesmente que "um é de seda, e o outro de lã". Notamos aqui a utilização de uma historieta em tom de relato com a finalidade de evidenciar o pensamento defendido pelo autor, caracterizando um artifício da narratio retórica (LAUSBERG, 1967).

Para ressaltar que a expressão nada teria com o idioma francês, Machado cita o poeta defensor da língua portuguesa Filinto Elísio (1734-1819), afirmando que este não encararia o termo como usual de "francelhos", como chamava os galicistas, ou de "tarelos", nome que dava a outros tagarelas afrancesados. O cronista se apropria das alusões que Castro Lopes faz às duas nomenclaturas no artigo Neologismo indispensável - Preconício, de 27 de fevereiro de 1889, sendo que a segunda denominação foi impressa no jornal como "tareco". Todavia, apesar da descoberta, o cronista adverte que adotou o "focale" assim que este apareceu, admitindo que "bastou ser romano, para abrir mão do outro que era apenas nacional”. O vocábulo de raiz latina é colocado ironicamente em posição de maior prestígio em relação ao termo aportuguesado. $\mathrm{O}$ "preconício" recebe tratamento parecido. A generalização ligada ao motivo da composição deste neologismo é logo questionada. Em seu artigo, Castro Lopes afirma que para "todos os homens de letras que falam a língua portuguesa, foi sempre manifestada a dificuldade de dar naquela língua o termo equivalente à palavra francesa - Reclame”. Já o colunista de Bons Dias! confessa que nunca se encontrou em tal dificuldade, relembrando seu passado enquanto relojoeiro:

Quando exercia o oficio (que deixei por causa da vista fraca), compunha anúncios grandes e pomposos. Não faltava quem me acusasse de fazer reclame para vender os relógios. Ao que eu respondia sempre:

- Faça-me o favor de falar português. Reclamo é o que eu emprego, e emprego muito bem; porque é assim que se chama o instrumento com que o caçador busca atrair as aves; às vezes, é uma ave ensinada para trazer as outras ao laço. Se não quer reclamo, use chamariz, que é a mesma coisa. E olhe que isto não está em livros velhos de jesuítas, anda já nos dicionários (Gazeta de Notícias, 7 mar. 1889).

$\mathrm{Na}$ antiga profíssão, o personagem cronista criado por Machado de Assis contentava-se com as palavras "reclamo" e "chamariz", correlatos nacionais do "reclame" francês, para designar a divulgação de seu trabalho. Ele demonstra que tinha reprovação ao termo advindo 


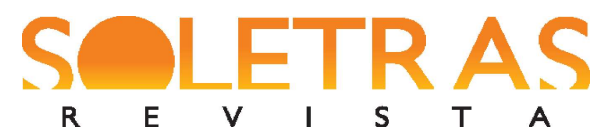

N. 40 - 2020.2 - VALNIKSON VIANA OLIVEIRA

SOCORRO DE FÁTIMA PACÍFICO BARBOSA

da língua francesa, preferindo adotar as versões aportuguesadas, já dicionarizadas naquela época. Todavia, novamente informa que abriu mão dos termos "nossos" em razão do neologismo alatinado. Machado demonstra se aproveitar da persona do relojoeiro para dissimular sua opinião sobre o neologismo.

Os "nasoculos" criados pelo famoso filólogo a fim de indicarem a função e não a forma do objeto para auxiliar a visão também foram acolhidos pelo colunista, em referência ao artigo Neologismo indispensável - Cache-Nez, 3 de março de 1889. Ele, que usou o "pince-nez" por muito tempo, foi tratar do enfraquecimento da vista diretamente na fábrica, procurando saber em Portugal sobre a "luneta-pêncil" inventada pelo escritor Camilo Castelo Branco (18251890). Segundo Gledson (2008), tal instrumento aparece no conto "O filho natural", publicado em 1876. Informado de que o objeto nacional havia perdido para o concorrente francês, continuou com o velho "pince-nez" que tanto lhe comia a vista e apertava o nariz. Percebemos que a narratio retórica foi novamente aplicada. Ademais, Machado ou Boas Noites, assim que viu os "nasoculos" criados pelo Dr. Castro Lopes, não tardou a largar do produto francês:

Era francês, mas, não cuidando a indústria nacional de o substituir, não havia eu de andar às apalpadelas. Vai senão quando, vejo anunciados os nasoculos do nosso distinto autor. Lá fui comprar um, já o cavalguei no nariz, e não me fica mal. Daqui a pouco, ver-me-ão andar pela rua, teso como um petitmaitre... Perdão, petimetre, que é já da nossa língua e do nosso povo (Gazeta de Notícias, 7 mar. 1889).

Na conclusão da crônica, ele adota o análogo português do galicismo "petit-maître" para informar que, partindo do uso dos sofisticados "nasoculos", logo o veriam com demasiada elegância pelas ruas, à semelhança do "petimetre", indivíduo requintadamente elegante, outro termo dicionarizado e popular. O colunista deixa finalmente entrever sua finalidade textual de provocar a reflexão dos leitores e persuadi-los a seguirem o seu pensamento. Para ele, os neologismos originados do latim seriam desnecessários na medida em que já haveria ou poderia haver palavras da língua portuguesa correlatas aos estrangeirismos. Ao longo da crônica, por meio de pequenas narrativas, vemos uma sucessão de ciclos sempre iniciados pela apresentação do galicismo criticado por Castro Lopes, passando pela apresentação de um equivalente 


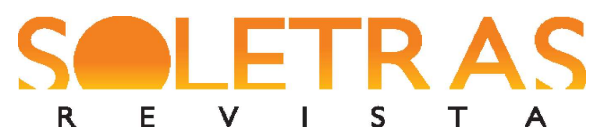

N. 40 - 2020.2 - VALNIKSON VIANA OLIVEIRA

SOCORRO DE FÁTIMA PACÍFICO BARBOSA

português e culminando na supressão deste equivalente em razão de um neologismo. O autor da crônica, antes de sempre fingir aprovar os novos vocábulos, utilizando a simulatio retórica, mostra como eles são fruto de um purismo exagerado e ligado a questões de prestígio. Entretanto, no último exemplo, um galicismo não citado em nenhum dos artigos publicados até então na Gazeta de Notícias é apenas substituído pela sua forma portuguesa, esta que realmente, em suas palavras, faria parte "da nossa língua e do nosso povo". O cronista se mostra a favor do aportuguesamento dos vocábulos estrangeiros e não de sua completa aniquilação em favor de vernaculismos. A sentença colocada ao fim da crônica constitui um epifonema retórico, resumindo o juízo de valor que ele pretendia transmitir aos leitores (LAUSBERG, 1967, p. 238).

No início da crônica do dia 22 de março de 1889, Machado de Assis revela suspeitar que as investidas linguísticas de Castro Lopes tenham o fim secreto de colocar o povo a falar volapuk, língua artificial criada para a comunicação internacional em 1879 pelo alemão Johann Martin Schleyer. Tal desconfiança, segundo ele, não seria de nenhum desrespeito tanto à memória latina quanto ao filólogo, mas pautada na falta de interesse deste em procurar os correlatos existentes na língua portuguesa aos estrangeirismos que tanto criticava antes de recorrer à feitura de seus neologismos alatinados. Ou o latinista desdenhava da língua nacional, ao contrário do que propagava, ou possuía a intenção secreta mencionada. A menção ao idioma artificial trata com jocosidade a viabilidade do projeto linguístico empreendido pelo filólogo, ao mesmo tempo em que realiza uma comparação, a similitudo retórica, entre a língua não natural e as propostas reformistas inviáveis (LAUSBERG, 1967).

Boas Noites brinca, em seguida com alguns dos vocábulos novos divulgados nos artigos da Gazeta até aquele momento, afirmando que se não estivesse falando volapuk ao pôr os "nasoculos" e ao comprar um "focale" e um "lucivelo" para fazer "preconício" na "concião", estaria certamente falando cartaginês, fazendo referência aos escritos. Assim, ele acrescenta ao elenco de galicismos condenados o termo "abajur", citado no artigo Neologismos indispensáveis $V$ - Abajur, de 11 de Março de 1889, além do primeiro anglicismo a ser criticado pelo Dr. Castro Lopes, a expressão “metting”, do artigo Neologismo indispensável VI - Meeting, de 18 de Março de 1889. Algo interessante a se notar é que o artigo em que este último estrangeirismo aparece foi escrito em 15 de março de 1889, o primeiro depois da publicação da primeira crônica de Machado de Assis que discutia as suas ideias de reforma linguística (em 7 
de março de 1889). ${ }^{8}$ Podemos inferir que a escolha de enfoque em um termo da língua inglesa denuncia uma possível reação do estudioso latinista à acusação que sofreu de direcionar suas críticas apenas aos termos franceses.

Voltando à crônica de Bons Dias!, Machado retoma o tom mais sério e diz que tudo produzido até então pelo filólogo foi sempre puro latim. Entretanto, aponta que, para o último galicismo criticado por ele, "aplomb", citado no artigo Neologismo indispensável VII - Plomb, de 20 de março de 1889, em vez de um neologismo, foi lembrada a existência de um termo equivalente da língua portuguesa que já se encontrava nos dicionários. Em novo maneirismo retórico, vemos que o autor realiza uma transferência semântica entre um fato típico da vida humana, o exemplo da senhora que encontra sua manta, e o seu pensamento propriamente dito, no caso, a ideia de se achar palavras esquecidas do português num momento oportuno.

Não há neologismo propriamente, já porque a palavra desempeno existia na língua, bastando apenas aplicá-la, já porque no sentido de aplomb lá a pôs no seu dicionário o nosso velho patrício Moraes. Contudo, foi bom serviço lembrá-la. Às vezes, uma senhora não sai bem vestida de casa por esquecimento de certa manta de rendas, que estava para um canto. Acha-se a manta, põe-se, a pessoa nada pediu emprestado e sai catita (Gazeta de Notícias, 22 mar. 1889).

O referido artigo de Castro Lopes trazia um curioso diálogo rimado entre o próprio vernaculista e um "francelho", lembrando muito a estrutura das crônicas de Machado em $A+B$ e Gazeta de Holanda. No escrito, o latinista explica que a expressão "aplomb”, que designa retidão e nivelamento, seria "prumo" em tradução para o português e que sua versão em sentido figurado, indicando elegância, garbo e desenvoltura, seria "desempeno", palavra já existente por aqui, mas esquecida. Podemos perceber novamente outra possível resposta em tom sutil e respeitoso do filólogo à primeira crônica de Bons Dias!, com a opção pela tradução e pelo resgate da "prata da casa" em detrimento da formação de um neologismo baseado no latim, apontada por Boas Noites como desnecessária. Contudo, é levantada a dúvida em relação à

\footnotetext{
${ }^{8}$ Os artigos de Castro Lopes publicados na Gazeta de Notícias apresentam ao seu final a data em que foram escritos, indicando que geralmente eram editados no jornal algum tempo depois ao momento de sua produção.
} 


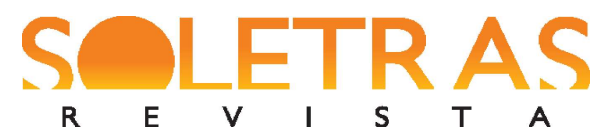

N. 40 - 2020.2 - VALNIKSON VIANA OLIVEIRA

SOCORRO DE FÁTIMA PACÍFICO BARBOSA

eficácia da aplicação do antes abandonado "desempeno" para arrancar o galicismo do uso cotidiano e parlamentar. Em reação, o cronista então indica uma versão mais aportuguesada daquela traduzida por Castro Lopes, com o acréscimo do prefixo "a-", trazendo nossa fisionomia ao galicismo, o que resultaria em uma incorporação ao idioma com maior probabilidade de permanência. A alternativa pelo vocábulo "aprumo" revela uma opinião menos extremada a respeito dos estrangeirismos, mostrando a possibilidade real de que estes poderiam ser absorvidos na língua naturalmente, sem a necessidade de nenhuma intervenção linguística.

Note-se que não estou inventando nada. Rebelo da Silva, homem de boas letras, escreveu esse vocábulo aprumo, e dizem que também anda em dicionários. Lá diz o Rebelo: "Respondendo... com o aprumo do homem seguro de ter cumprido etc. etc." Vá lá, desmamemos o galicismo, e demoslhe depois um bom bife de desempeno. É verdade que podemos vir a ficar com as duas palavras, para a mesma ideia, coisa só comparável a ter duas calças, quando uma só veste perfeitamente um homem (Gazeta de Notícias, 22 mar. 1889).

A metáfora das calças tem o mesmo efeito retórico do exemplo da senhora com a manta esquecida, aproximando o pensamento do autor ao público leitor. Machado admite que os dois termos, tanto o traduzido quanto o aportuguesado, podem circular como sinônimos, apesar de continuar assinalando a sua opção, que "vestiria mais perfeitamente" o povo. Contudo, ele aponta que esta seria uma questão para o tempo. Curiosamente, o artigo estreante publicado em 27 de fevereiro de 1889, Neologismo indispensável - Preconício, traz a imagem da roupa que causa estranheza em comparação ao neologismo empreendido por Castro Lopes.

Próximo ao final da crônica, Machado alfineta o próprio periódico que o publica, afirmando que se a Gazeta de Notícias tem a intenção de durar mais tempo, “aceitará o esforço generoso de alguém que bote o intruso para fora a pontapés". Ele faz alusão ao prestígio que o jornal possivelmente desfrutava ao editar os artigos do famoso filólogo, abrigando suas ideias tão excludentes. Com esta passagem, podemos verificar que, apesar de toda a limitação espacial dentro do jornal, as dimensões da crônica eram abrangentes, permitindo com que os escritores pudessem queixar-se de qualquer coisa, inclusive do suporte que abrigava seus escritos. 
Ademais, a liberdade advinda do gênero precisaria ser utilizada com habilidade e competência. A grande exposição da reforma linguística empreendida por Castro Lopes é assinalada na passagem seguinte, em que o colunista diz desconfiar que as ideias do latinista já andariam em livros de outros autores. Logo depois, ele alega não possuir certeza de nada e demonstra outra vez deixar tudo nas mãos do tempo, concluindo com a última ária da ópera $O$ Barbeiro de Sevilha (1816), de Gioachino Rossini (1792-1868): "Ecco ridente in cielo / Già spunta la bella aurora..." (Aqui, rindo no céu / Já emerge o belo amanhecer...). O trecho serve para reforçar a ideia de que o tempo trataria de mostrar quem teria razão diante do que foi exposto.

Já a crônica de 20 de abril de 1889 começa com Boas Noites inferindo sobre os estudos da língua que, segundo ele, não acarretariam a perda da pele, nem da paciência, muito menos das ilusões. Ele reforça sua dedução comparando tais estudos com os voltados à política, que seriam como a Dalila por quem Sansão perdeu o cabelo e por quem André Roswein, da peça escrita por Octave Feuillet (1821-1890), perdeu a vida. Ele ainda garante que nunca perderá seus dias em razão do "ilustre latinista", que continuava a compor novas locuções para expelir "barbarismos". Para o cronista, a língua tanto não seria fatal, que nos permitiria errar e aprender com os erros. Assim, ele não se recrimina por usar a pouco o seu "chambre".

Cuidei estar composto, sem escândalo. Não ignorava (tanto que já o disse aqui mesmo) que aquele vestido, antes de passar a fronteira, era robe de chambre; ficou só chambre. Mas como vinha de trás, os velhos que conheci não usavam outra coisa, e o próprio Nicolau Tolentino, posto que mestre-escola, lá o enfiou nos seus versos, pensei que não era caso de o desbatizar (Gazeta de Notícias, 20 abr. 1889).

Machado lembra que, na crônica de 7 de março de 1889, havia citado o "robe de chambre" francês. Ao contrário do que demonstrou naquele escrito, aqui admite claramente o uso da peça de roupa, colocando que sua terminologia seria antiga, estando inclusive nos versos do poeta satírico Nicolau Tolentino (1740-1811). Se o galicismo já estava tão incorporado à nossa língua portuguesa, ao ponto de já registrar até uma versão simplificada, qual seria a necessidade de rebatizá-lo? Ele completa assegurando em tom jocoso que nunca mandou embora uma "caleça", palavra usada para designar o cocheiro, apenas por vir do francês 


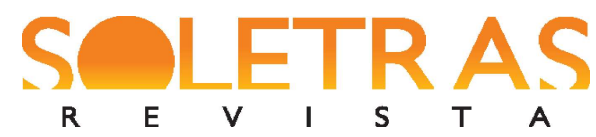

N. 40 - 2020.2 - VALNIKSON VIANA OLIVEIRA

SOCORRO DE FÁTIMA PACÍFICO BARBOSA

"caleche", deixando no máximo alguma vez de lhe dar a gorjeta. O cronista, em seguida, diz ter se espantado com o artigo que condenava o "chambre" por ser galicismo. Como mencionado anteriormente, esse escrito não pertence à série publicada por Castro Lopes na Gazeta, mas ao livro deste autor, Neologismos indispensáveis e barbarismos dispensáveis (1889). O escritor fluminense conta que logo jogou para longe a estrangeirice e vestiu um "paletó", sem reparar que também se tratava de um termo francês, o que reforçou sua "ignorância". As pessoas que ainda utilizavam os estrangeirismos diante da intervenção do latinista também eram atacadas por ele nos artigos, o que é informado indiretamente através de uma faceta "medrosa" do autor da crônica. Voltando ao roupão, este estaria permitido, mas com o nome de "rocló", apresentada pelo filólogo Castro Lopes como uma expressão portuguesa antiga. O colunista então decide aderir ao termo:

Com efeito, se os nossos maiores chamavam de rocló ao chambre, melhor é empregar o termo de casa, em vez de ir pedi-lo aos vizinhos. O contrário é desmazelo. Chamei então o meu criado - que é velho e minhoto - e disse-lhe que daqui em diante, quando lhe pedisse o rocló, devia trazer-me o chambre. (Gazeta de Notícias, 20 abr. 1889).

A tradução clássica empregada pelos ancestrais seria preferível aos vocábulos novos, cuja aplicação direta apontaria preguiça e desleixo. Entretanto, o criado do personagem cronista, chamado Inácio, acabaria por revelar a verdade por trás da mudança de palavras. Vemos novamente o uso do artifício retórico da narratio. Boas Noites conta que o servo informou-lhe rindo que, em Portugal, "rocló" seria "um capote curto, estreito e de mangas", bem diferente do "chambre", afirmando que inclusive serviu um homem em Lisboa que usava as duas peças: o "chambre" de manhã, em casa, e o "rocló" com "manguinhas enfiadas" à noite. Não acreditando no que havia acabado de ouvir, o relojoeiro pediu para que ele jurasse que tudo aquilo era verdade. $\mathrm{O}$ velho se ofendeu e, às lagrimas, pediu as contas ao patrão que, o deixando de lado, passou a cogitar um modo de advertir o povo sobre o "rocló" que não era "chambre", seu principal objetivo com esta crônica. Para o autor da crônica, "a ignorância da língua e o amor da novidade dão certo sabor a vocábulos inventados ou descabidos". Como poderia prevenir as pessoas sem citar o depoimento daquele ancião desprovido de autoridade? 


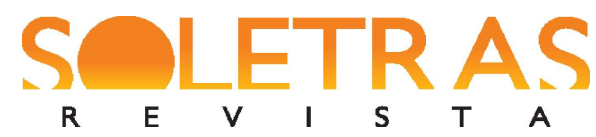

N. 40 - 2020.2 - VALNIKSON VIANA OLIVEIRA

SOCORRO DE FÁTIMA PACÍFICO BARBOSA

Machado de Assis percebe que o termo "rocló" viria de "roquelaure", designação francesa de um capote. Portugal havia recebido da França a peça capote e o seu nome, ficando com ambos, mas modificando tal nome para uma forma mais simples, assim como o termo "robe de chambre" que virou apenas "chambre". A substituição proposta não teria sentido, ao menos que Castro Lopes quisesse "curar a dentada do cão com o pelo do mesmo cão", ou seja, eliminar o galicismo através de outro galicismo. Ele finaliza a crônica citando o célebre princípio da Homeopatia: "Similia similibus curantur" (O semelhante pelo semelhante se cura). Vemos de novo a utilização de um epifonema retórico ao fim do raciocínio argumentante, também constituindo uma referência irônica ao fato de que o latinista seria adepto desse tratamento médico alternativo, tendo lançando inclusive alguns livros tematizando o assunto.

\section{Considerações finais}

Observando a elaboração discursiva das três crônicas de Machado de Assis selecionadas para este estudo, podemos constatar a ênfase dada à inventio, processo que consiste no ato de encontrar pensamentos adequados conforme o interesse do partido representado, pensamentos estes que serviriam como instrumentos intelectuais e afetivos para obter, pela persuasão, a vitória do partido representado. Não se trata de um processo de criação, visto que os pensamentos já existiriam no subconsciente ou na semiconsciência do orador, sendo encontrados por meio da recordação (LAUSBERG, 1967). O autor faz constante referência a grandes nomes da literatura portuguesa e da história, além de selecionar personagens ilustres e obras clássicas para complementar seu argumento. Claro que as menções intertextuais não constituíam meras ilustrações, guardando significados que contribuíam para o tom jocoso das crônicas ou que elucidavam melhor alguma passagem.

O cronista inicia os escritos sempre com a simpática saudação "Bons Dias!", concluindo-os com um educado "Boas Noites", mostrando cordialidade e boas maneiras. Tal polidez de discurso constitui uma técnica retórica para a conquista do público. A boa apresentação e a despedida gentil serviriam como estratégias para a identificação do leitor com a persona do autor. A linguagem mais coloquial característica do gênero transmite maior naturalidade ao que é escrito, também constituindo um instrumento retórico de elocução. A 


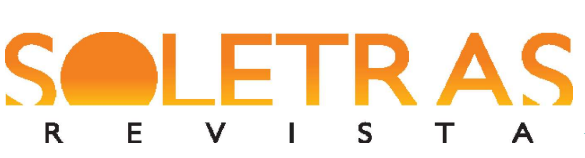

comunicação nas crônicas de Bons Dias! tem ar de espontaneidade semelhante à simplicidade do relato oral, objetivando atrair a atenção dos interlocutores. A informalidade na linguagem também é marcada pela grande ocorrência de diálogos e narrações que permitem a presença da fala transcrita. É interessante também notar que o cronista quase sempre se refere aos estrangeirismos como se fossem as próprias expressões ou objetos que representavam, provavelmente tentando mostrar o quanto já estavam absorvidos pelo cotidiano nacional. É como se, para ele, a modificação de um termo também transformasse o que ele designava.

Percebemos que as crônicas analisadas se estruturam em três partes de acordo com a dispositio retórica, que é formada pela escolha e pela ordenação favoráveis ao partido (LAUSBERG, 1967). Vemos que a parte inicial, ou exórdio, visa atrair a atenção, a boa aceitação e a benevolência dos leitores para a causa partidária defendida. Machado inicia os escritos analisados sempre com alguma indagação jocosa, seduzindo o público ao mesmo tempo em que o introduz à temática. A parte central é formada pela propositio, que consiste na exposição daquilo que se quer provar, e a argumentatio, a comprovação do que foi alegado, de forma objetiva, convencendo intelectualmente, ou afetiva, persuadindo emocionalmente. É nesta parte que notamos o frequente uso do artifício da simulatio, com o autor fingindo ingenuidade e aprovação sobre as ideias de Castro Lopes, visando apresentar os resultados de suas meditações, e da narratio, através da narração de histórias curtas substanciando tais reflexões de forma direta e agradável. A parte final dos escritos corresponde à peroratio e apresenta como certo (ou que dará certo) aquilo que foi provado (LAUSBERG, 1967). Direta ou indiretamente, o autor finaliza as crônicas ressaltando o seu ponto de vista em relação ao que foi por ele questionado, aumentando a propensão do leitor a refletir e concordar com a sua opinião.

Gledson (2008) aponta que o nacionalismo de Machado de Assis na esfera linguística estava, assim como em outras áreas, temperado pela realidade. O autor das crônicas via nas ideias empreendidas por Castro Lopes uma tentativa de pôr freio à dinamicidade da língua portuguesa, desrespeitando sua história e seus falantes. O idioma português não estaria em perigo, visto que os empréstimos vocabulares eram naturais e imprescindíveis ao diálogo com outras culturas. Forjar palavras baseadas na raiz latina para substituir termos estrangeiros tomados por razões comunicacionais relevantes era algo desnecessário. Ademais, para o referido cronista, seria bom se, em vez de um neologismo, o filólogo propusesse alguma 
tradução ou um correlato aportuguesado. Era o que acontecia com as importações normalmente: iam ganhando nossa identidade com o tempo, sem qualquer intervenção reformista, mas de acordo com as circunstâncias reais de uso. Para Machado, a "estrangeirice" dos estrangeirismos seria apagada aos poucos pela própria língua.

\section{Referências}

ASSIS, M. Bons dias!. In: Gazeta de Notícias, 20 abr. 1889. Ano XV, n. 66, p. 1. Bons dias! In: Gazeta de Notícias, 22 mar. 1889. Ano XV, n. 81, p. 1. . Bons dias! In: Gazeta de Notícias, 7 mar. 1889. Ano XV, n. 110, p. 1.

. Obra Completa, em quatro volumes. Org. Aluizio Leite Neto, Ana Lima Cecilio, Heloisa Jahn. Rio de Janeiro: Nova Aguilar, 2008, v. 4.

BARBOSA, S. F. P. A escrita epistolar, a literatura e os jornais do século XIX: uma história. Revista Anpoll, 2011. v. 1, n. 30. p. 261-291. Disponível em: $<$ http://www.anpoll.org.br/revista/index.php/revista/article/viewArticle/196>. Acesso em: 03 fev. 2015.

BETELLA, G. K. Bons dias: o funcionamento preciso da inteligência em terras de relógios desacertados: as crônicas de Machado de Assis. Rio de Janeiro: Revan, 2006.

BORTOLANZA, J. O Poeta novilatino carioca António de Castro Lopes (1827-1901). In: Revista Humanitas (Coimbra), 1999. v. LI, n. 1. p. 301-316. Disponível em: <https://digitalisdsp.uc.pt/jspui/bitstream/10316.2/28192/1/Humanitas51_artigo12.pdf $>$. Acesso em: 03 fev. 2015.

CAMARA JUNIOR, J. M. Princípios de linguística geral. Rio de Janeiro: Padrão, 1989.

CANDIDO, A. A vida ao rés do chão. In: CANDIDO, A. et al. A crônica: o gênero, sua fixação e sua transformação no Brasil. Campinas: Unicamp, 1992. p. 13-22.

O francês como instrumento de desenvolvimento. In: CANDIDO, A. et al. O francês instrumental, a experiência na Universidade de São Paulo. São Paulo: Hemus, 1977, p. 9-17.

CARVALHO, J. M. História intelectual no Brasil: a retórica como chave de leitura. Revista Topoi, 2000. $\quad$ n. $1, \quad$ p. 123-152. Disponível em: $<$ http://www.ifcs.ufrj.br/ ppghis/pdf/topoila3.pdf>. Acesso em: 03 fev. 2015. 
FARIAS, V. L. C. Machado de Assis na imprensa do século XIX: práticas, leitores e leituras. Tese (Doutorado em Letras), Programa de Pós-Graduação em Letras - PPGL, Universidade Federal da Paraíba - UFPB. João Pessoa: 2013.

FREYRE, G. Ingleses no Brasil. Rio de Janeiro: Topbooks, 2000.

GLEDSON, J. Introdução. In: ASSIS, M. Bons dias! São Paulo: Unicamp, 2008.

GRANJA, L. Machado de Assis, escritor em formação (à roda dos jornais). Campinas, SP: Mercado das Letras, 2000.

Domínio da boa prosa: narradores e leitores na obra do cronista. In: Cadernos de Literatura Brasileira: Machado de Assis. São Paulo: Instituto Moreira Salles, 2008. n. 23/24. p. 252-272.

LAUSBERG, H. Elementos de retórica literária. Lisboa: Fundação Calouste Gulbenkian, 1967.

LOPES, A. C. Neologismo indispensável - Preconício. In: Gazeta de Notícias, 27 de fevereiro de 1889. Ano XV, n. 58, p. 2.

. Neologismo indispensável II - Pince-Nez. In: Gazeta de Notícias, 3 de março de 1889. Ano XV, n. 62, p. 2.

. Neologismo indispensável III - Cache-Nez. In: Gazeta de Notícias, 4 de março de 1889. $\overline{\text { Ano XV }}$, n. 63, p. 2.

. Neologismos indispensáveis V - Abajur. In: Gazeta de Notícias, 11 de março de 1889. Ano XV, n. 70, p. 2.

. Neologismo indispensável VI - Meeting. In: Gazeta de Notícias, 18 de março de 1889. Ano XV, n. 77, p. 2.

. Neologismo indispensável VII - Plomb. In: Gazeta de Notícias, 20 de março de 1889. Ano XV, n. 79, p. 2.

MAGALHÃES JÚNIOR, R. Prefácio. In: ASSIS, M. Diálogos e Reflexões de um Relojoeiro: escritos de 1886 (“A + B”), de 1888 e 1889 ("Bons dias"), recolhidos da "Gazeta de Notícias". Rio de Janeiro: Ediouro, 1985. p. 15-23. (Coleção Prestígio).

. Vida e obra de Machado de Assis: maturidade. Rio de Janeiro: Record, 2008. v. 3.

MARTINS, N. S. Introdução à estilística: a expressividade na língua portuguesa. São Paulo: Edusp, 2008. 
MEYER, M. Voláteis e versáteis: de variedades e folhetins se fez a chronica. In: CANDIDO, A. et al. A crônica: o gênero, sua fixação e suas transformações no Brasil. Campinas: Unicamp, 1992. p. 93-134.

PEREIRA, L. M. Machado de Assis: estudo crítico e biográfico. Belo Horizonte: Itatiaia, 1998.

RIBEIRO, M. P. A reforma ortográfica da Academia Brasileira de Letras, em 1907. Revista da Academia Brasileira de Filologia, 2011. n. 9. p. 206-210. Disponível em: $<$ http://www.filologia.org.br/abf/rabf/9/206.pdf $>$. Acesso em: 03 fev. 2015.

SÁ, J. A crônica. São Paulo: Ática, 1985. (Série Princípios)

\title{
Castro Lopes and the chronicle of Machado de Assis: linguistic discussion on the pages of Gazeta de Noticias
}

\begin{abstract}
This article aims to demonstrate how the writer Machado de Assis (1839-1908) contributed to the formation of the chronic literary genre in Brazil, using the dimensions and scope of the newspaper support. We specifically approach his positions regarding the proposals of Castro Lopes (1827-1901), a famous philologist of the late 19th century who proposed replacing, in Portuguese, some foreign words with new words, created by himself mostly from Latin. To this end, we will analyze three chronicles published under a pseudonym and whose authorship was attributed to the author from Rio de Janeiro, in 1955. The chronicles of the Bons Dias! Series, launched in the periodical Gazeta de Noticias between the years 1888 and 1889 , mainly dealt with the great political events of the time, which makes the three selected writings as isolated from this theme. Thus, we show that the author of these chronicles, through an essentially rhetorical discourse, tried to persuade his readers to reflect on the ideas of the mentioned Latinist. To support our work, we mainly use Candido (1992) and Meyer (1992) regarding the study of the chronicle, as well as Lausberg (1967), to understand the techniques of rhetoric. We also supported our analysis in Farias (2013), Gledson (2008), Barbosa (2011), Betella (2006) and Magalhães Júnior $(1985 ; 2008)$.
\end{abstract}

Keywords: Machado de Assis. Castro Lopes. Gazeta de Notícias. chronicle. rhetoric.

Recebido em: 04 de março de 2020.

Aceito em: 26 de junho de 2020. 